\title{
Anaemia and its associated factors among pregnant women in rural area of North India
}

\author{
Akashdeep Singh Chauhan, Manoj Kumar Sharma, Hoshiar Singh Chauhan \\ Correspondence: Dr Akashdeep Singh Chauhan, PhD Scholar, School of Public Health, Post \\ Graduate Institute of Medical Education and Research, Sector-12, Chandigarh - 160012, \\ India; Email - akashchauhan23@gmail.com
}

Distributed under Creative Commons Attribution-Share Alike 4.0 International.

\begin{abstract}
Objective: The aim of the present study is to determine the prevalence of anaemia among pregnant women and its association across socio-demographic and other risk factors. Methodology: It was a cross-sectional study conducted in the Faridkot district of Punjab. A total of 594 pregnant women were enrolled by consecutive sampling. Data were collected through semi-structured interview schedule and haemoglobin estimation was done using Sahli's method. Results: The prevalence of anaemia was found to be $89.7 \%$ (with 55.4\% and $34.3 \%$ of pregnant women having moderate anaemia and mild degree of anaemia). No case of severe degree of anaemia was reported. Prevalence of anaemia was significantly $(\mathrm{p}<0.05)$ higher among women belonging to the scheduled castes, middle income groups and those who went out in the fields for open defecation. Conclusion: In addition to preventive programs against anaemia, the study highlights the need for dietary counselling and nutritional education among the pregnant women as well as their family members.
\end{abstract}

Keywords: Anaemia, haemoglobin, pregnant women, prevalence.

Anaemia is one of the major public health problem and common nutritional deficiency across the world ${ }^{1}$. It is especially prevalent in women of reproductive age group, particularly during pregnancy ${ }^{2,}{ }^{3}$. As per estimates, anaemia during pregnancy is present in around $14 \%$ of the pregnant women in developed countries and $51 \%$ in developing nations ${ }^{4}$. As per results of Indian Council of Medical Research Micronutrient survey, conducted across 16 districts in India, anaemia among pregnant women was found to be in the range of $33 \%$ and $89 \%$.
Anaemia is the second most common cause of maternal deaths across the world, out of which $20 \%$ of the total deaths are reported from India ${ }^{7}$. Also, this death constitutes $80 \%$ of the total maternal deaths in South Asian region ${ }^{8}$. Further, anaemia is also the $9^{\text {th }}$ leading cause of disability adjusted life years (DALY) loss among women of age group 15-49 years across the world ${ }^{4}$. Furthermore, anaemia causes various pregnancy related complications such as premature labour, poor weight gain and dysfunctional labour, low birth weight, foetal and neonatal distress ${ }^{9-11}$.

Received: $1^{\text {st }}$ January 2017. Accepted: $13^{\text {th }}$ April 2017.

Chauhan AS, Sharma MK, Chauhan HS. Anaemia and its associated factors among pregnant women in rural area of North India. The New Indian Journal of OBGYN. 2017; 4(1): 10-6 
Iron and folate deficiency is seen as one of the major cause of anaemia among the women of reproductive age group. This deficiency is related to either low dietary intake of these nutrients or poor bioavailability or chronic blood loss during infections such as malaria and hookworm infestations ${ }^{12}$. Considering this, Government of India launched an iron supplementation program i.e., National Nutritional Anaemia Prophylaxis Program (NNAP) in 1970 during the fourth 5-year health plan with the aim of reducing anaemia among the women of reproductive age group ${ }^{13}$. Under this program a minimum dose of 100 iron and folic acid tablets (IFA) during the period of pregnancy had been recommended. In addition to this, IFA tablets are also being distributed to pregnant women as a part of service package under RCH (Reproductive and child health) program since 1997, which has now been modified to RMNCHA program ${ }^{14}$. Further, recently introduced Weekly iron folic acid scheme (WIFS) distributes IFA tablets to adolescent/teenage girls to improve their anaemic status before they enter the reproductive age group ${ }^{15}$.

Despite all these efforts, anaemia stills remain prevalent across India. The present study hypothesized that various socio-demographic and risk factors during pregnancy could be the barriers in front of the efforts put in place for the prevention of anaemia. In view of the above, the present study was planned to determine the prevalence of anaemia among pregnant women and study its association across socio-demographic and other pregnancy related risk factors in rural area of Faridkot district of Punjab, India.

\section{Material and Methods}

It was a descriptive cross sectional study conducted in the rural area of Faridkot district of Punjab. There are 2 blocks in the Faridkot district i.e., Baja Khana and Jand Sahib with 37 and 25 sub health centres in each block respectively, with a total of 62 sub centres in the district. All the pregnant women coming for their ante natal check-ups (ANC) at the sub centre irrespective of their gestational age and previous ANC visits were considered eligible for the study. Systematic random sampling was adopted to select every $3^{\text {rd }}$ sub health centre in the study. Thus, a total of 20 sub centres were shortlisted i.e., 12 from Baja Khana and 8 from Jand Sahib. A total of 594 pregnant women were enrolled in the study by consecutive sampling method during 2 months period from April to May 2012. A pre-tested, semi-structured interview schedule was used for data collection. Socio-demographic information like age, marital status, educational status, occupation, source of drinking water and defecation facility and other relevant risk factors like number of children, gestational period, pregnancy gap and intake of iron folic acid supplements by the pregnant women were collected using this schedule. Written informed consent was obtained before starting of any interview with the patient. Ethical clearance was obtained from the Institutional Ethical Committee of Baba Farid University of Health Sciences, Faridkot.

Haemoglobin estimation was done by Sahli's method by a trained laboratory technician and Sahli's haemoglobinometer was used to determine haemoglobin level ${ }^{16,17}$. Typing of anaemia was done as per standard peripheral blood smear examination. Anaemia was classified as per WHO (World Health Organization) criteria. According to this classification, haemoglobin $(\mathrm{Hb})$ concentration level below by 11.0 $\mathrm{gm} / \mathrm{dl}$ was considered as anaemia during pregnancy. $\mathrm{Hb}$ concentration level in the range of $10.0-10.9 \mathrm{gm} / \mathrm{dl}$, $7.0-10.0 \mathrm{gm} / \mathrm{dl}$ and less than $7.0 \mathrm{gm} / \mathrm{dl}$ were labelled as mild, moderate and severe degree of anaemia respectively ${ }^{18}$.

Data entry and analysis was done in SPSS version 17. Frequency distribution and chi-square tests were applied to see the association between anaemia and selected socio-demographic and other pregnancy related risk factors. $\mathrm{P}$ value of less than 0.05 was taken as statistically significant.

\section{Results and Observations}

Out of total sample, around half of the women were in the age group of 21-25 years $(n=318,53.5 \%)$ with the mean age of around 23.9 years (SD: 3.04). Around $60 \%$ of these women belonged to the scheduled caste category $(n=368), 51 \%$ had primary or middle level of education ( $n=173), 39 \%$ used storage tank as a source 
of drinking water and $69 \%(n=402)$ belonged to the families where either agriculture or daily wage labour was the main source of income (Table 1). The sample was divided into income quintiles based on the annual income of the households of the pregnant women.

Thirty eight percent $\quad(n=224)$ of the pregnant women belonged to the primigravida group followed by $1 / 3^{\text {rd }}$ $(n=193)$ in the second, and the remaining in the third and above gravida. As far as parity is concerned, nullipara was most commonly reported (46\%).

Among those women, who had given previous birth $(\mathrm{n}=316), 18-36$ months was the most common birth interval (44\%). Around 94\% (559) of the women had consumed iron folic acid tablets (IFA) during the current pregnancy and 6\% (n=37) had undergone abortion during previous pregnancies (Table 2 ).

Out of total sample, $89.7 \%(\mathrm{n}=533)$ were anaemic, with mild and moderate anaemia in $34.3 \%(n=204)$ and
Table-1: Anaemia and associated socio demographic factors

\begin{tabular}{|c|c|c|c|c|c|}
\hline \multirow[t]{2}{*}{ Variable } & \multirow[t]{2}{*}{ Category } & $\begin{array}{l}\text { Overall } \\
(\mathrm{N}=594)\end{array}$ & $\begin{array}{l}\text { Presence of } \\
\text { Anaemia } \\
(\mathrm{N}=533)\end{array}$ & $\begin{array}{l}\text { Absence of } \\
\text { anaemia } \\
(\mathrm{N}=61)\end{array}$ & \multirow[t]{2}{*}{$\begin{array}{l}P \\
\text { value }\end{array}$} \\
\hline & & $\mathbf{N}(\%)$ & & & \\
\hline \multirow[t]{4}{*}{ Current age } & $<21$ years & $77(100)$ & $67(87)$ & $10(13)$ & \multirow{4}{*}{0.741} \\
\hline & 21-25 years & $355(100)$ & 318 (89.6) & 37 (10.4) & \\
\hline & 26-30 years & $145(100)$ & $132(91)$ & $13(9)$ & \\
\hline & $>30$ years & $17(100)$ & $16(94)$ & $1(6)$ & \\
\hline \multirow{3}{*}{$\begin{array}{l}\text { Age at } \\
\text { marriage }\end{array}$} & $<21$ years & $355(100)$ & $320(90)$ & $35(10)$ & \multirow[t]{3}{*}{0.855} \\
\hline & $21-25$ years & $226(100)$ & $201(89)$ & $25(11)$ & \\
\hline & $>25$ years & $13(100)$ & $12(92.3)$ & $1(7.7)$ & \\
\hline \multirow[t]{3}{*}{ Caste } & Scheduled caste & $368(100)$ & $338(92)$ & $30(8)$ & \multirow[t]{3}{*}{0.029} \\
\hline & Backward class & 67 (100) & $61(91)$ & $6(9)$ & \\
\hline & General & $159(100)$ & $134(84)$ & $25(16)$ & \\
\hline \multirow{4}{*}{ Education } & Illiterate & $109(100)$ & $103(94.5)$ & $6(5.5)$ & \multirow[t]{4}{*}{0.285} \\
\hline & Primary & $173(100)$ & $155(90)$ & $18(10.4)$ & \\
\hline & Middle & $129(100)$ & $115(89)$ & $14(11)$ & \\
\hline & Matriculation and above & $183(100)$ & $160(87)$ & $23(17)$ & \\
\hline \multirow{5}{*}{$\begin{array}{l}\text { Income } \\
\text { quintiles }\end{array}$} & Poorest & $130(100)$ & $112(86)$ & $18(14)$ & \multirow[t]{5}{*}{0.015} \\
\hline & Poor & $111(100)$ & $107(96)$ & $4(4)$ & \\
\hline & Middle & $120(100)$ & $109(91)$ & $11(9)$ & \\
\hline & Rich & $131(100)$ & $120(92)$ & $11(8)$ & \\
\hline & Richest & $102(100)$ & $85(83)$ & $18(17)$ & \\
\hline \multirow{4}{*}{$\begin{array}{l}\text { Source of } \\
\text { water }\end{array}$} & Common storage tank & $232(100)$ & $207(89)$ & $25(11)$ & \multirow[t]{4}{*}{0.115} \\
\hline & Hand pump & $223(100)$ & $206(92)$ & $17(8)$ & \\
\hline & Well & $11(100)$ & $11(100)$ & 0 & \\
\hline & R.O. & $128(100)$ & $109(85)$ & $19(15)$ & \\
\hline & Agriculture & $174(100)$ & $151(87)$ & $23(13)$ & \multirow[t]{4}{*}{0.187} \\
\hline \multirow{3}{*}{$\begin{array}{l}\text { Occupation } \\
\text { of the } \\
\text { household }\end{array}$} & Business & $135(100)$ & $127(94)$ & $8(6)$ & \\
\hline & Service (Pvt/Govt) & $46(100)$ & $40(87)$ & $6(13)$ & \\
\hline & Labour & $239(100)$ & $215(90)$ & $24(10)$ & \\
\hline \multirow{3}{*}{$\begin{array}{l}\text { Defecation } \\
\text { facility }\end{array}$} & Flush system & $415(100)$ & $364(88)$ & $51(12)$ & \multirow[t]{3}{*}{0.034} \\
\hline & Soak pit & $135(100)$ & $126(93)$ & $9(7)$ & \\
\hline & Open space & $44(100)$ & $43(98)$ & $1(2)$ & \\
\hline
\end{tabular}

$55.4 \%(n=329)$ of the women respectively (Table 3 ). None of the women was found to be severely anaemic. The mean $\mathrm{Hb}$ level was $10.17 \mathrm{~g} / \mathrm{dl}$ (SD 1.278). Further, median level of $\mathrm{Hb}$ was $9.8 \mathrm{~g} / \mathrm{dl}$ with a range from 7$13.8 \mathrm{~g} / \mathrm{dl}$.

Anaemia was statistically $(\mathrm{p}<.05)$ higher among women belonging to the scheduled castes (92\%), 
backward class $(91 \%)$, middle income groups (poor: 96\%; middle: $91 \%$ ) and those who went into the field for defecation (98\%) as shown in the table 1. A nearly

\section{Discussion}

The present study was undertaken in the rural area of Punjab to assess the prevalence of anaemia among pregnant women. The results showed that $90 \%$ of the sampled pregnant women were anaemic with around $62 \%$ of them having moderate anaemia. The high prevalence of anaemia in the state of Punjab, is consistent with the finding of a previous studies $19,20$. One of these studies showed $84 \%$ of the pregnant women being anaemic ${ }^{19}$ while other showed prevalence of anaemia as $89 \%$ among adolescent girls 20 .

significant high prevalence $(\mathrm{p}=0.07)$ was reported among women in the multiparous group (95\%) as compared to nulliparous $(87 \%)$ or primiparous group (90.4\%) (Table 2).

Further, anaemia was also higher among those women who were aged $>30$ years $(94 \%)$, illiterate (95\%), used well (100) or hand pump (92\%) as a

\section{Table-3: Prevalence of Anaemia}

\begin{tabular}{llll}
\hline \multicolumn{2}{l}{ Severity of anaemia } & N (\%) & Overall (\%) \\
\hline \multicolumn{2}{l}{ No Anaemia } & $61(10.3)$ & $61(10.3)$ \\
Anaemia & Mild Anaemia & $204(34.3)$ & $533(89.7)$ \\
& Moderate Anaemia & $329(55.4)$ & \\
& Severe Anaemia & 0 & \\
Overall & & $594(100)$ & $594(100)$ \\
\hline
\end{tabular}

When compared to other states of India, the prevalence of anaemia among the pregnant women ranged from $75 \%-100 \%{ }^{21-24}$, showing a similar type of picture across the nation. However, when compared to developing countries of Tanzania, Nigeria and Sudan ${ }^{25-27}$, anaemic among pregnant women was reported to be low, i.e., in the range of $60-77 \%$. This suggests that there certain factors specific to Indian context, which need to be studied and controlled in addition to only implementing iron supplementation programs.

The study showed high prevalence of anaemia among women who were illiterate, belonged to socially deprived communities (scheduled caste and backward class) and lower income groups. The findings are similar to those reported from the studies conducted in Delhi ${ }^{28}$, Kashmir ${ }^{23}$ and Maharashtra ${ }^{21}$, where both education and income status was inversely linked to the prevalence of anaemia. Scheduled castes and backward class are considered socially and educationally disadvantaged communities in the Indian 
society ${ }^{29,30}$. Further, in the Indian culture, as scheduled castes comes low in the ladder as compared to other castes, these are considered inferior and neglected part ${ }^{29}$. Low community status and lack of social support from the society could create barriers against access to appropriate health knowledge and health care for women belonging to these deprived communities. Further this type of discrimination along with low economic status forced the women from these families to be dependent upon their routine staple diet, even during the period of pregnancy. Moreover, women who are illiterate, have low knowledge on the role of diet and nutrition and lack of confidence in decision making capacity in choosing the appropriate diet ${ }^{31}$. The present study also showed that women belonging to families, who went for open defecation or drank water directly from storage tanks or wells, were more anaemic. As results showed seen that $93 \%$ and $86 \%$ of the total families who went for open defection or used storage tanks/wells belonged either to scheduled castes or backward class, strengthened the fact of having low awareness and socio-economic power among these communities in having appropriate knowledge and capacity to build hygienic amenities.

The present study showed a proportional relationship with increasing age and anaemia, similar to the findings from the studies done in Maharashtra ${ }^{21}$, Aurangabad ${ }^{32}$, and Kashmir valley ${ }^{23}$. Further, women who were multiparous or had undergone previous abortions were reported to more anaemic. It could be that women having history of any of the above factor or both, might had suffered from acute or chronic periods of blood loss during previous pregnancies, were not properly been supplemented there after and entered as blood deficient in their next pregnancy.

Government of India started various iron supplementation programs such National Nutritional Anaemia Prophylaxis Program (NNAP) in $1970{ }^{13}$, Reproductive and child health (RCH) in $1997^{14}$ and a recent one in the form of Weekly iron folic acid scheme (WIFS) ${ }^{15}$. Under all these programs, iron and folic acid tablets are distributed free of cost to pregnant women and adolescent girls. As expected, women who consumed these tablets should have better haemoglobin levels. However, in the present study it was reported that women who consumed these tablets, still had higher prevalence of anaemia. One of the reasons could be that these tablets were consumed only by those who were severely anaemic and during the present study their haemoglobin levels were improved and they were reported as mild or moderately anaemic. The other reason could be lack of adherence in completing the full course of IFA tablets as $70 \%$ of the women who consumed these tablets, did not complete the full course as recommended in guidelines.

\section{Conclusion}

Although no severe case of anaemia was reported, but still very high prevalence of anaemia $(89.7 \%)$ was found. There is a need for dietary counselling and nutritional education in antenatal clinics, so that women, who are illiterate or belong to low socioeconomic strata, could get appropriate and timely knowledge about this issue. Further, family members of these pregnant women should also be counselled about the health of the mothers not only during pregnancy but post pregnancy period also.

\section{Conflict of interest: None. Disclaimer: Nil.}

\section{References}

1.DeMayer EM, Tegman A. Prevalence of anaemia in the World. World Health Organ Qlty. 1998; 38: 302-16.

2.March of dimes. Pregnancy and Newborn, complication of Anaemia during pregnancy [Internet]. 2013 [cited 2013 Sep 20]. Available from: http://www.marchoftimes.org/complications/pregnancycomplications.aspx.

3.Kalaivani K. Prevalence and consequences of anaemia in pregnancy. Indian J Med Res. 2009; 130(5): 627-3.

4.World Health Organization. Global Health Estimate: DALY by Age, Sex and cause [Internet]. 2014[cited 2014 Jan 27]. Available from:

http://www.who.int/healthinfo/global_burden_disease/esti mates/en/index 2.html.

5.Toteja GS, Singh P, Dhillon BS, Saxena BN, Ahmed FU, Singh RP, et al. Prevalence of anemia among 
pregnant women and adolescent girls in 16 districts of India. Food Nutr Bull. 2006 ; 27(4): 311-5.

6.Toteja GS, Singh P. Micronutrient profile of Indian population. New Delhi: Indian Council of Medical Research; 2004.

7.Government of India. Health information of India. New Delhi: DGHS, Nirmal Bhawan; 1995.

8.Ezzati M, Lopus AD, Dogers A, Vander HS, Murray C. Selected major risk factors and global and regional burden of disease. Lancet. 2002; 360:1347-60.

9.Roy S, Chakravorty PS. Maternal and perinatal outcome in severe anaemia. J Obstet Gynae Ind.1992; 42:743-50. .

10.Rangnekar AG, Darbari R. Foetal outcome in anaemia during pregnancy. J Obstet Gynae Ind. 1993; 43:172-6.

11.Prema K, Neela Kumari S, Ramalakshmi BA. Anaemia and adverse obstetric outcome. Nutr Rep Int. 1981; 23: 637-43.

12.National Nutrition Monitoring Bureau (NNMB). NNMB Micronutrient survey. Hyderabad: National Institute of Nutrition; 2002.

13.Agarwal DK, Agarwal KN, Roychaudhary S. Targets in national anaemia prophylaxis programme for pregnant women. Indian Pediatr.1988; 25: 319-22.

14.Ministry of Health and Family Welfare, Government of India, National Health Mission. Maternal health [Internet]. 2015[cited 2015 Oct 02]. Available from: http://nrhm.gov.in/nrhm-components/rmnch-a/maternalhealth/background.html.

15.Ministry of Health and Family Welfare, Government of India, National Health Mission.

Reproductive,maternal,newborn,child and adolescent health [Internet]. 2015[cited 2015 Oct 02]. Available from: http://nrhm.gov.in/nrhmcomponnets/reproductivechild-health/adolescenthealth/wifs.html.

16.Sanyal S. Clinical Pathology: Prep manual for undergraduates. New Delhi: Elsevier India Private limited; 2005. p. 25.

17.Godkar PB, Godkar DP. Textbook of Medical Laboratory Technology. 2nd edn (reprinted). Mumbai: Bhalani Publishing; 2011.

18.World Health Organization. Vitamin and Mineral Nutrition Information System, Haemoglobin concentrations for the diagnosis of anaemia and assessment of severity. [Internet]. 2015[cited 2015 Aug
3]. Available from:

http://www.who.int/vmnis/indicators/haemoglobin.pdf.

19. Chaudhar MK, Akaram H, Mubeen A. Prevalence of Anemia in Pregnant Women in Central Punjab. 2011.

20.Gupta VK, Maria AK, Kumar R, Bahia JS, Arora S. To Study the Prevalence of Anaemia in Young Males and Females with Respect to the Age, Body Mass Index (BMI), Activity Profile and the Socioeconomic Status in Rural Punjab. Journal of Clinical and Diagnostic Research. 2011; 5(5): 1020-26.

21.Ahmad N, Kalakoti P, Bano R, Syed MMA. The prevalence of anaemia and associated factors in pregnant women in a rural Indian community. Australas Med J. 2010; 3(5): 276-80. Doi 10.4066/AMJ.2010.286.

22. Viveki RG, Halappanavar AB, Viveki PR, Halki SB, Maled VS, Deshpande PS. Prevalence of anaemia and its epidemiological determinants in pregnant women. $\mathrm{Al}$ Ameen J med Sci. 2012; 5(3): 216-23.

23.Kaul R, Ahmad J, Baba TA, Sheikh S, Ahmad A, Ashraf M, et al. Anaemia in pregnant women in a rural block of Kashmir valley: its prevalence and sociodemographic associates. Int J Med Sci Public Health. 2013; 2: 814-18.

24.Vemulapalli B, Rao KK. Prevalence of anaemia among pregnant women of rural community in Vizianagram, North coastal Andhra Pradesh, India. Asian J Med Sci. 2014; 5(2): 21-5.

25.Hinderaker SG, Olsen BE, Bergsjo P, Lie RT, Gasheka $\mathrm{P}$, Kwale G. Anemia in pregnancy in the highlands of Tanzania. Acta Obstet Gynecol. 2001; 80: 18-26.

26.Iloabachie GC, Meniru GI. The increasing incidence of anemia in pregnancy in Nigeria. Orient J Med. 1990; 2: 194 - 97.

27.Adam I, Khamis AH, Elbashir MI. Prevalence and risk factors for anemia in pregnant women of Eastern Sudan. Trans R Soc Trop Med Hyg. 2005; 99: 739-43.

28. Gautam VP, Bansal Y, Taneja D, Saha R. Prevalence of anaemia amongst pregnant women and its sociodemographic associates in a rural area of Delhi. Indian Journal of Community Medicine. 2002; 27(4): 157.

29. Karade J. Development of scheduled castes and scheduled tribes in India: Cambridge Scholars Publishing; 2009.

30.Deshpande A, Ramachandran R. How backward are the other backward classes? Changing contours of caste 
The New Indian Journal of OBGYN. 2017 (July-December); 4(1)

disadvantage in India. Center for Development

Economics Working Papers. 2013; 233.

31.Medel-Anonuevo C. Women, Education and Empowerment: Pathways towards Autonomy. UIE Studies 5: ERIC; 1995.

32.Lokare PO, Karanjekar VD, Gattani PL, Kulkarni AP. A study of prevalence of anaemia among pregnant women in Aurangabad city, India. Ann Nigerian Med. 2012; 6: 30-4.

Akashdeep Singh Chauhan ${ }^{1}$, Manoj Kumar Sharma ${ }^{2}$, Hoshiar Singh Chauhan ${ }^{3}$

${ }^{1}$ School of Public Health, Post Graduate Institute of Medical Education and Research, Chandigarh, India; ${ }^{2}$ Centre for Public Health, Punjab University, Chandigarh, India; ${ }^{3}$ Centre for Public Health and Health Care Administration, College of Health \& Allied Sciences, Eternal University, Baru Sahib, Himachal Pradesh, India. 